\title{
AVALIAÇÃO QUALIQUANTITATIVA DOS RISCOS EXISTENTES EM UMA OFICINA MECÂNICA LOCALIZADA EM CAMPO MOURÃO/PR
}

\author{
Larissa de Carvalho ${ }^{l *}$, Jordana Dorca dos Santos ${ }^{2}$, Fernanda Santos Silveira ${ }^{l}$, Daniele Martins de Almeida \\ Lilian Aparecida Martins ', Tamara da Silva ', Ana Carla Fernandes Gasques ${ }^{3}$ \\ ${ }^{1}$ Curso de Engenharia de Produção Agroindustrial, Universidade Estadual do Paraná, 87302-060, Campo Mourão, Brasil. \\ 2 Departamento de Engenharia de Produção Agroindustrial, Universidade Estadual do Paraná, 87302-060, Campo Mourão, Brasil. \\ ${ }^{3}$ Departamento de Engenharia de Produção, Universidade Estadual de Maringá, 87020-900, Maringá, Brasil.
}

*E-mail: larissadecarvalho9@gmail.com

\section{RESUMO}

A saúde e a segurança do trabalho se tornaram uma grande preocupação tanto para os colaboradores quanto para as organizações, tendo em vista que sua prevenção e controle contribuem para a redução de acidentes e para a melhoria das condições de trabalho. Diante disso, os objetivos deste trabalho consistem em realizar uma avaliação qualiquantitativa dos riscos existentes em uma oficina mecânica situada no município de Campo Mourão/PR e propor sugestões de melhorias para os riscos identificados. Para tal, as técnicas de pesquisas utilizadas foram: bibliográfica, por levantamento, estudo de caso e estudo de campo. Foi possível constatar que a empresa em questão fornece treinamentos, equipamentos de proteção individual e equipamentos de proteção coletiva para os colaboradores. Em relação aos riscos, foram identificados riscos de acidentes, ergonômicos, físicos e químicos. Sobre a percepção da segurança do trabalho pelos colaboradores, constatou-se que estes acreditam que as atividades exercidas não acarretam em problemas de saúde e o trabalho não é considerado estressante. Ainda segundo os colaboradores, a situação considerada mais crítica vivenciada no dia a dia é o desconforto térmico. De modo geral, a oficina está devidamente sinalizada, o que demonstra uma preocupação com a saúde e a segurança dos seus colaboradores e dos seus clientes.

Palavras-chave: Oficina mecânica. Segurança do trabalho. Acidentes de Trabalho.

\section{Introdução}

Antigamente, a segurança, a higiene e o conforto dos colaboradores não eram prioridade para as organizações, cujo foco era o lucro proveniente da grande exploração da mão de obra. Porém, esse cenário mudou e, atualmente, a saúde e a integridade do trabalhador são fatores essenciais para que as organizações tenham um bom funcionamento [1].

As atividades desenvolvidas nos ambientes de trabalho, muitas vezes, proporcionam ao colaborador situações de deficiências ergonômicas ou riscos de acidentes de trabalho, podendo ocasionar lesões, doenças ou até mesmo morte, além de prejuízos legais e patrimoniais para as organizações [2].

No Brasil, segundo o Artigo $2^{\circ}$ da Lei 6.367, de 19 de outubro de 1976, "acidente do trabalho é aquele que pode ocorrer pelo exercício do trabalho a serviço da empresa, provocando lesão corporal ou perturbação funcional que cause a morte, perda, ou redução, permanente ou temporária, da capacidade para o trabalho" [3].

Além da Constituição Federal e das legislações trabalhistas da Consolidação das Leis do Trabalho (CLT), a legislação básica relacionada à segurança do trabalho está contida nas Normas Regulamentadoras (NRs) [4]. As NRs são um conjunto de requisitos e procedimentos que se referem à segurança e medicina do trabalho, sendo obrigatórios em empresas privadas, públicas e órgãos do governo que possuem empregados regidos pela CLT [5].

A partir do exposto, constata-se que a segurança no trabalho é de grande importância tanto para o colaborador quanto para a empresa, tendo em vista que possibilita uma prevenção de possíveis acidentes que podem trazer prejuízos para ambas as partes. Manter a segurança no ambiente de trabalho proporciona uma melhor relação entre o empregador e o empregado, pois demonstra o quanto a organização se preocupa com a saúde, o bem-estar e a integridade de seu colaborador [6].

Diante do exposto, a presente pesquisa teve por objetivos realizar uma avaliação qualiquantitativa dos riscos existentes em uma oficina mecânica situada no município de Campo Mourão/Paraná e propor sugestões de melhorias para os riscos identificados. 


\section{Referencial Teórico}

Neste capítulo são apresentados conteúdos teóricos que fornecem suporte para a pesquisa desenvolvida. Foram abordados assuntos relacionados a: acidentes do trabalho no Brasil; setor de oficinas mecânicas; riscos de acidentes; programas de prevenção de acidentes; e legislação vigente.

\subsection{Acidentes de trabalho no Brasil}

No Brasil, de acordo com o Anuário Estatístico da Previdência Social de 2015, ocorreram aproximadamente 613 mil acidentes durante o ano, sendo que do total de acidentes registrados com Comunicado de Acidente de Trabalho (CAT), os acidentes típicos representaram 76,28\%; os de trajeto $21,08 \%$ e as doenças do trabalho $2,63 \%$ [7].

$\mathrm{O}$ acidente de trabalho típico é aquele que ocorre no exercício do trabalho, face à ocorrência de fato súbito e violento, provocado por uma causa exterior a um colaborador [8].

$\mathrm{O}$ acidente de trajeto é aquele que ocorre quando o colaborador se desloca a serviço da empresa, podendo ser o trajeto residência-trabalho ou vice-versa e também uma atividade a serviço da empresa fora do ambiente de trabalho [9].

A doença do trabalho é aquela desenvolvida pelo exercício do trabalho peculiar a determinada atividade ou profissão [10].

Além do sofrimento gerado às vítimas e suas famílias, os acidentes também acarretam em prejuízos às empresas e à sociedade como um todo. Em 2015, a Previdência Social desembolsou cerca de $\mathrm{R} \$ 4,3$ milhões em benefícios, dos quais $85,5 \%$ eram previdenciários, $6,4 \%$ assistenciais e $5,1 \%$ acidentários [7]. As espécies mais concedidas foram o auxíliodoença previdenciário, a aposentadoria por idade e o saláriomaternidade com, respectivamente, $42,1 \%, 13,3 \%$ e $12,9 \%$ do total [7].

\subsection{Setor de Oficinas Mecânicas}

O mercado consumidor dos serviços prestados pelas oficinas mecânicas é geralmente constituído pelos proprietários particulares de automóveis e frotistas, isto é, empresas ou pessoas que possuem carros, órgãos públicos, seguradoras, dentre outros [10].

Atualmente, esse mercado está cada vez mais movimentado e competitivo, fato esse que se justifica com a entrada de franquias especializadas na reparação de veículos, com grandes estruturas de atendimento em redes espalhadas por todo o país. Além disso, há um novo comportamento de compra de carros importados e populares: a classe alta consome carros estrangeiros, o que demanda conhecimento específico das oficinas, enquanto a classe média troca de carro antes que este comece a apresentar problemas, reduzindo, assim, o trabalho de consertos mecânicos [11].
Assim como em outros setores da indústria, as oficinas mecânicas são ambientes em que os trabalhadores enfrentam inúmeros riscos durante a execução de suas tarefas. O uso de substâncias tóxicas como o benzeno, soluções de baterias e gases de petróleo são alguns exemplos dos perigos enfrentados na manutenção de veículos [12].

Os riscos aos quais os trabalhadores estão sujeitos são responsáveis por colocá-los em situações de vulnerabilidade à ocorrência de acidentes. A atividade mecânica no Brasil apresenta números significativos de acidentes do trabalho. Em 2015 ocorreram cerca de 1.498 acidentes de trabalho relacionados a serviços de manutenção e reparação mecânica de veículos automotores, todos registrados no Instituto Nacional de Seguridade Social [7].

\subsection{Riscos de Acidentes}

Os riscos de acidentes do trabalho podem ser reunidos em três grupos, sendo eles [13]:

a) Físicos: ocorre quando o colaborador está exposto às diversas formas de energia, tais como: ruído, vibrações, pressões anormais, temperaturas extremas, radiações ionizantes, radiações não ionizantes, bem como o infrassom e o ultrassom;

b) Químicos: ocorre quando o colaborador está exposto às substâncias, compostos ou produtos que possam penetrar no organismo pela via respiratória, nas formas de poeiras, fumos, névoas, neblinas, gases ou vapores, ou que, pela natureza da atividade de exposição, possam ter contato ou ser absorvidos pelo organismo através da pele ou por ingestão;

c) Biológicos: ocorre quando o colaborador está exposto às bactérias, fungos, bacilos, parasitas, protozoários, vírus, entre outros.

Além desses três grupos, existem os riscos ergonômicos e de acidentes, sendo que os primeiros são aqueles relacionados ao esforço físico, monotonia, jornada prolongada, levantamento e transporte manual de peso, e os segundos são condições de instalação e funcionamento de uma organização, bem como suas máquinas e equipamentos que não apresentam condições de uso adequadas para o colaborador, podendo causar acidente [14].

A implantação de medidas preventivas, como a utilização adequada de equipamentos de proteção individual e coletiva, pode reduzir os altos índices de acidentes de trabalho nas organizações [12].

\subsection{Programas de prevenção de acidentes}

O Programa de Prevenção de Riscos Ambientais (PPRA) prevê a obrigação de implementação de um programa de preservação da saúde dos trabalhadores por parte dos empregadores e tem como objetivo prevenir a saúde e a integridade dos trabalhadores, por meio da antecipação, reconhecimento, avaliação e controle de riscos ambientais de determinado local [13]. 
A Comissão Interna de Prevenção de Acidentes (CIPA) tem por objetivo observar e relatar os riscos existentes nos ambientes de trabalho e solicitar medidas para reduzi-los ou eliminá-los [15].

Formada por representantes e por colaboradores, A CIPA é obrigatória em empresas com mais de 20 colaboradores e tem por missão preservar a saúde e a integridade física dos colaboradores de uma empresa [15].

O Serviço Especializado em Engenharia de Segurança e Medicina do Trabalho (SESMT) é o setor que faz parte do organograma interno das organizações e está submetido às ordens da empresa contratante, bem como à constante fiscalização do Ministério do Trabalho e Emprego, este que é composto por profissionais especializados na área de segurança e medicina do trabalho [16].

O SESMT é responsável por aplicar conhecimentos de engenharia para eliminar os riscos no ambiente; determinar o uso de Equipamentos de Proteção Individual (EPI's); atuar nos projetos físicos e tecnológicos; fazer cumprir as NRs; interagir com a CIPA e dar todo suporte necessário; desenvolver programas de educação e capacitação dos trabalhadores, entre outras funções [16].

O Programa de Controle Médico de Saúde Ocupacional (PCMSO) tem por finalidade prevenir, rastrear e diagnosticar precocemente as doenças ocupacionais, envolvendo ações de toda a equipe, em especial, do médico do trabalho [17].

O PCMSO deve ser elaborado por um médico do trabalho independente do número de colaboradores da organização. Para sua elaboração deve ser feito um estudo prévio para reconhecimento dos riscos ocupacionais existentes na empresa, por meio de visitas aos locais de trabalho, baseando-se nas informações contidas no PPRA e no Mapa de Riscos [17].

\subsection{Legislação vigente}

A Lei $n^{\circ}$ 15.297, aprovada em janeiro de 2014, estabelece normas básicas a serem seguidas pelos proprietários e responsáveis por oficinas mecânicas e estabelecimentos assemelhados que prestam serviços de manutenção, conserto ou substituição de peças em veículos automotores leves, novos ou usados [11].

Dentre essas normas básicas, tem-se o código: NBR 15.681 - Veículos rodoviários automotores e qualificação de mecânico de manutenção [18]; código: NBR 14.778 - Veículos rodoviários automotores em manutenção - inspeção, diagnóstico, reparação e/ou substituição em sistema de freios e o código [19]; NBR 10.004 - Resíduos sólidos e as Normas regulamentadoras [20]; NR 6 - Equipamento de proteção individual [21]; NR 7 - Programa de Controle Médico de Saúde Ocupacional - PCMSO e NR 9 - Programa de Prevenção de Riscos Ambientais - PPRA [11].

\subsection{Equipamentos de proteção}

Uma das maneiras eficazes de minimizar os riscos aos quais os trabalhadores estão expostos, ao exercerem as suas atividades laborais, consiste na utilização correta dos EPI's [22]., que são dispositivos usados individualmente para proteger a integridade física do trabalhador e podem eliminar ou mesmo mitigar a exposição a suscetíveis riscos e ameaças à segurança e à saúde, tais como agentes infecciosos, químicos, calor ou frio excessivo [23].

\section{Metodologia}

O presente estudo foi realizado em uma oficina mecânica localizada no município de Campo Mourão/PR.

\subsection{Técnicas de Pesquisas}

As técnicas de pesquisas utilizadas foram bibliográfica, por levantamento, estudo de caso e estudo de campo: bibliográfica, pois teve como base artigos, monografias, dissertações, teses, anais de eventos, entre outros, referentes ao assunto abordado como fundamentação teórica; levantamento devido à entrevista realizada com o responsável pela oficina para coletar informações; estudo de caso, por ser um trabalho realizado na oficina mecânica; e estudo de campo, se justifica devido à coleta de dados ser realizada na empresa in loco.

\subsection{Técnicas de Coleta e Tratamento de Dado}

Para a coleta de dados, utilizou-se um roteiro de entrevista (Apêndice A), aplicado ao responsável da oficina, e que teve por finalidade identificar os programas de prevenção de segurança e saúde no trabalho realizados na empresa.

Também foi aplicado um questionário de percepção de riscos pela visão dos colaboradores (Apêndice B), para o diagnóstico dos riscos ocupacionais presentes na oficina. As questões do questionário foram elaboradas a partir das referências bibliográficas consultadas.

Foram realizadas medições de ruído e iluminância em cada setor (em triplicata), com o auxílio dos equipamentos (luxímetro digital Homis TES-1332AG) e ruído (decibelímetro Lutron SL-4001) para avaliação quantitativa e comparativa dos dados. Para realizar as medições, foram determinados pontos específicos da empresa, nos quais foram tomadas três medições.

Para a medição da iluminância, o luxímetro digital foi posicionado no ponto mais próximo dos equipamentos utilizados no posto de trabalho. Para fins de comparação foi utilizada a norma ABNT NBR ISO/CIE 8995-1:2013 que trata sobre iluminação de ambientes de trabalho.

O decibelímetro digital foi colocado na altura do ouvido dos colaboradores, sendo os valores obtidos comparados com o anexo I da NR 15, que trata sobre atividades insalubres. Para o processamento dos dados, elaboração dos gráficos e tabelas foram utilizados os programas Microsoft@ Office Excel 2007, Microsoft@ Office Word 2007. 


\subsection{Técnicas de Análise de Dados}

Para a análise dos dados foram realizados gráficos para identificar quais eram os principais fatores a serem discutidos pela percepção dos colaboradores. Além disso, foram tiradas fotos do local, a fim de analisar os riscos visuais.

\section{Resultados e discussões}

\subsection{Descrição das atividades}

O processo de serviço de reparo de carros (processo produtivo analisado) ocorre conforme apresentado na Figura 1, a seguir.

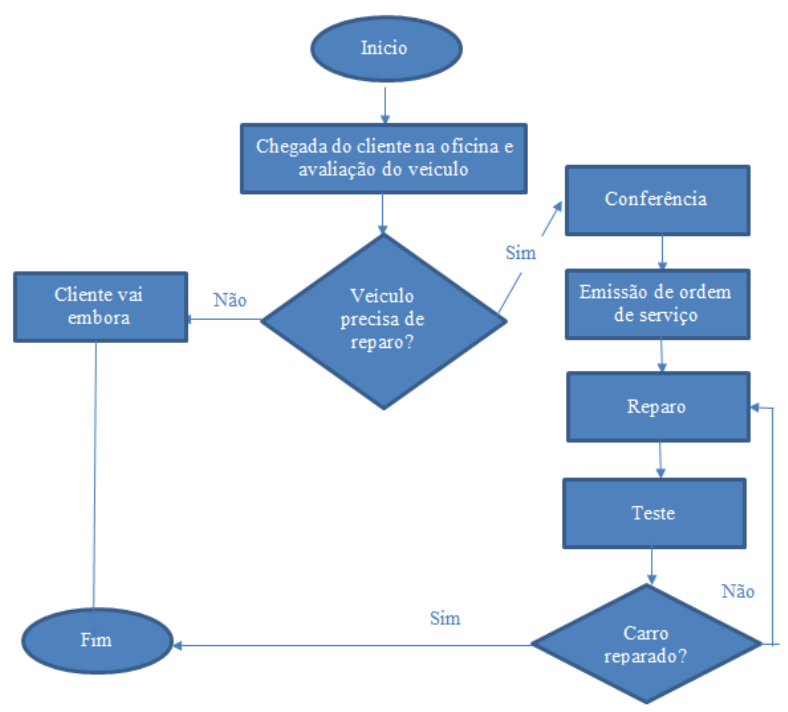

Figura 1 - Processo de serviço de reparo de carros.

O processo se inicia com a chegada do cliente na oficina para a avaliação do seu veículo. Se o veículo não precisar de reparo, o cliente vai embora e o processo se encerra; caso contrário, o veículo passa pela conferência, em seguida é emitida uma ordem de serviço, para então o veículo passar pelo reparo e teste. Se o veículo estiver reparado, o cliente vai embora e o processo se encerra; caso contrário, o veículo deve voltar para a etapa de reparo.

\subsection{A segurança do trabalho na organização}

Em relação à segurança do trabalho na empresa, constatou-se que ela fornece treinamentos sobre segurança no trabalho, realizados por empresas terceirizadas.

A Empresa possui CIPA, PPRA e PCMSO, porém não possui SESMT. Há um técnico de segurança do trabalho de uma empresa terceirizada que realiza vistorias para verificar a existência de riscos no ambiente de trabalho. Não foi identificada a existência de uma brigada de incêndio na empresa, porém, durante a semana da SIPAT, são fornecidos treinamentos a todos os colaboradores sobre como agir em casos de incêndio.

Os EPI's fornecidos pela empresa são: protetores de ouvido, óculos de segurança, luvas de lona leve, luvas de PVC, avental de lona, calçados de segurança, máscara semi facial, máscara para soldador, luvas de raspa. Os EPC's fornecidos pela empresa são: extintores de incêndio, kit de primeiros socorros e sistema de sinalização.

\subsection{Análise qualitativa dos ricos}

Após a visita à oficina mecânica e o acompanhamento das atividades realizadas pelos colaboradores, foi possível identificar quais os riscos existentes no ambiente de trabalho, os quais podem ser observados no Quadro 1.

Com relação aos riscos identificados, nota-se que não foi encontrado risco biológico. Em alguns casos, uma única situação ou atividade está relacionada a mais de um tipo de risco.

Quadro 1 - Identificação dos riscos existentes no ambiente de trabalho da oficina mecânica (continua...).

\begin{tabular}{|c|c|c|c|c|}
\hline \multirow{2}{*}{ Perigo } & \multicolumn{4}{|c|}{ Riscos } \\
\hline & Acidente & Ergonômico & Físico & Químico \\
\hline $\begin{array}{l}\text { Desmontagem e montagem de } \\
\text { peças }\end{array}$ & $\begin{array}{l}\text { Queda de peça ou } \\
\text { equipamento sobre algum } \\
\text { membro }\end{array}$ & $\begin{array}{l}\text { Postura inadequada para } \\
\text { realização da atividade e } \\
\text { carregar sobrecarga }\end{array}$ & - & $\begin{array}{l}\text { Produtos químicos em } \\
\text { contato com pele, olhos } \\
\text { e nariz }\end{array}$ \\
\hline $\begin{array}{l}\text { Lavagem de peças (produtos } \\
\text { químicos) }\end{array}$ & $\begin{array}{l}\text { Queda de peça ou } \\
\text { equipamento sobre algum } \\
\text { membro } \\
\text { Incêndio ou explosão }\end{array}$ & - & - & $\begin{array}{l}\text { Deixar respingos da } \\
\text { lavagem cair sobre olhos } \\
\text { e pele }\end{array}$ \\
\hline
\end{tabular}


Quadro 1 - Identificação dos riscos existentes no ambiente de trabalho da oficina mecânica (fim).

\begin{tabular}{|c|c|c|c|c|}
\hline $\begin{array}{l}\text { Manuseio de materiais e } \\
\text { ferramentas }\end{array}$ & $\begin{array}{l}\text { Queda do material ou } \\
\text { ferramentas sobre algum } \\
\text { membro }\end{array}$ & $\begin{array}{l}\text { Postura inadequada para } \\
\text { realização da atividade. } \\
\text { Carregar sobrecarga }\end{array}$ & - & - \\
\hline $\begin{array}{l}\text { Materiais combustíveis no local } \\
\text { de trabalho }\end{array}$ & Incêndio ou explosão & - & - & - \\
\hline Presença de gases tóxicos & - & - & - & Inalação de gases \\
\hline $\begin{array}{l}\text { Presença de líquidos no chão } \\
\text { (óleo, água, etc.) }\end{array}$ & Quedas no mesmo nível & - & - & $\begin{array}{l}\text { Produtos químicos em } \\
\text { contato com pele }\end{array}$ \\
\hline Presença de ruídos & - & - & $\begin{array}{l}\text { Exposição ao } \\
\text { ruído }\end{array}$ & - \\
\hline Teste de motores e outras peças & $\begin{array}{l}\text { Queda de peça ou } \\
\text { equipamento sobre algum } \\
\text { membro } \\
\text { Incêndio ou explosão }\end{array}$ & $\begin{array}{l}\text { Postura inadequada para a } \\
\text { realização da atividade }\end{array}$ & $\begin{array}{l}\text { Exposição a } \\
\text { ruídos }\end{array}$ & - \\
\hline $\begin{array}{l}\text { Trabalho árduo (estresse, } \\
\text { fadiga, cansaço, etc.) }\end{array}$ & $\begin{array}{l}\text { Diversos acidentes devido à } \\
\text { falta de atenção ou cansaço }\end{array}$ & - & - & - \\
\hline Utilização de elevador de carga & $\begin{array}{l}\text { Queda do veículo suspenso, } \\
\text { causando ferimentos, } \\
\text { esmagamento ou quebra de } \\
\text { membros ou objetos }\end{array}$ & - & - & - \\
\hline
\end{tabular}

Com relação ao ambiente de trabalho, existe uma desorganização de peças, ferramentas e materiais, o que pode contribuir para o risco de acidentes, devido a constante movimentação dos colaboradores (Figura 2).

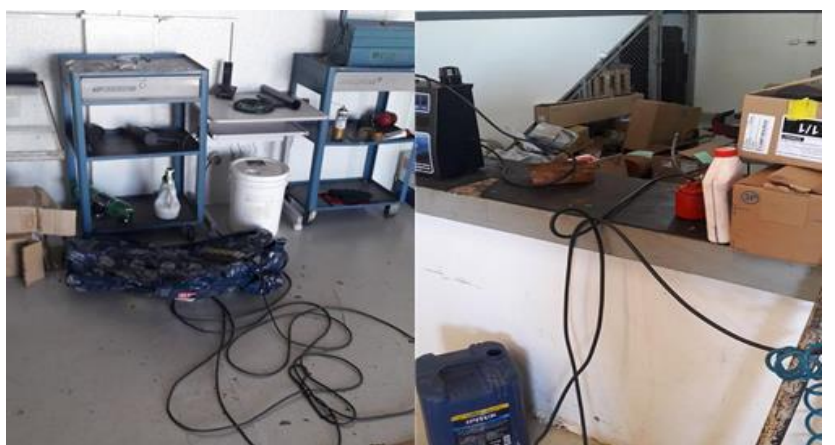

Figura 2 - Materiais e ferramentas desorganizados.

No que diz respeito à sinalização, observa-se a sinalização adequada quanto aos locais de alta tensão e presença de extintores e mecanismos para controle de incêndio (Figura 3).

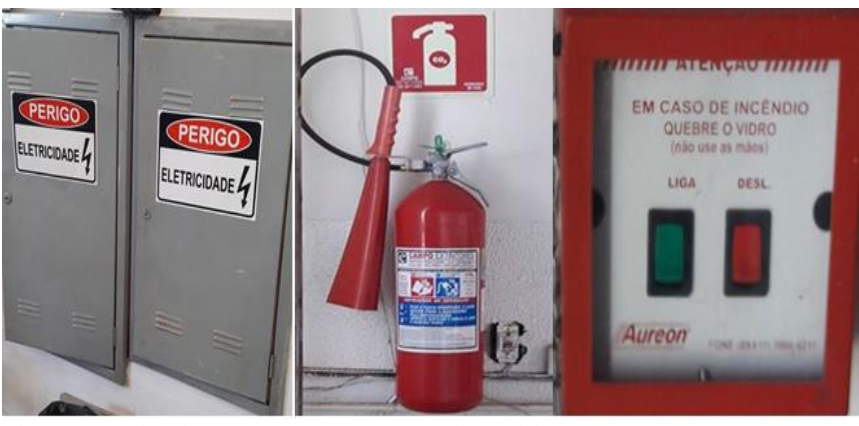

Figura 3 - Sinalização, equipamentos e dispositivos de controle.
A respeito das sinalizações, existem faixas que indicam o local adequado para a circulação dos pedestres (Figura 4). A oficina apresenta diversas placas de avisos, que se repetem em diferentes locais, como forma de reforço, contribuindo assim para a maior segurança dos colaboradores (Figura 5).

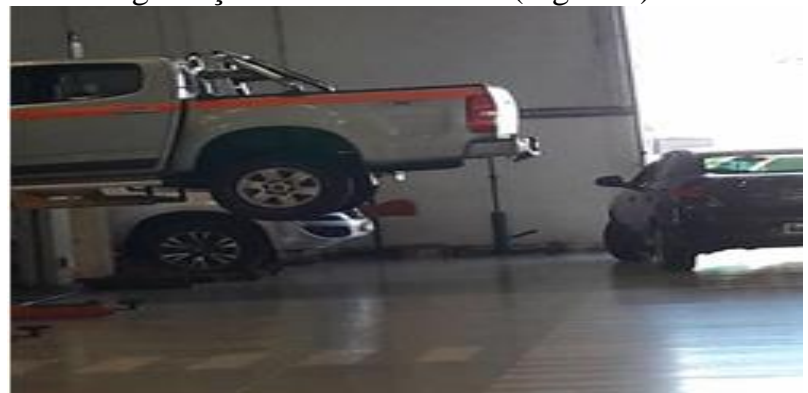

Figura 4 - Faixa para circulação de pedestres.

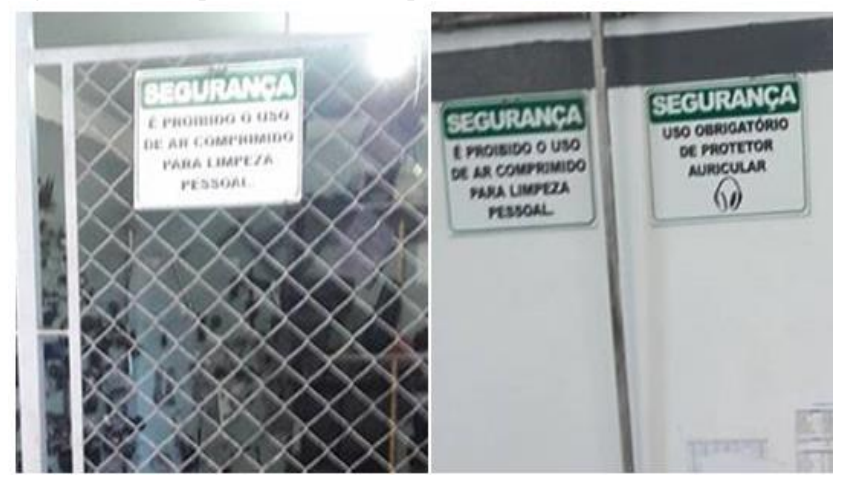

Figura 5 - Placas de aviso.

De modo geral, a oficina está devidamente sinalizada, o que demonstra uma preocupação com a saúde e a segurança dos seus colaboradores e clientes. No entanto, mediante à desorganização de alguns locais, sugere-se que a oficina adote 
práticas de organização do ambiente de trabalho, como por exemplo a adoção e o cumprimento da metodologia 5S, garantindo, assim, uma melhor apresentação do espaço físico perante os clientes, além de reduzir riscos de acidentes como quedas, ocasionados pela desordem.

\subsection{Análise quantitativa dos riscos (ruído e luminosidade)}

Foram realizadas medições do nível de iluminância e ruído do ambiente de trabalho da oficina mecânica, conforme apresentado nos Quadros 2 e 3.

Quadro 2 - Medições no nível de iluminância no ambiente de trabalho da oficina mecânica.

\begin{tabular}{|c|c|c|}
\hline & Medições & Padrão \\
\hline Ambiente. & $\begin{array}{c}\text { Iluminância } \\
\text { Escala 2000 } \\
\text { (LUX) }\end{array}$ & $\begin{array}{c}\text { Iluminância } \\
\text { ABNT 8995:2013 } \\
(\text { LUX })\end{array}$ \\
\hline Box 1 & $207 \pm 15,6$ & $300-500$ \\
\hline Box 5 & $150 \pm 6,7$ & $300-500$ \\
\hline Box 6 & $116 \pm 4,4$ & $300-500$ \\
\hline Box 10 & $370 \pm 20$ & $300-500$ \\
\hline Área de passagem & $293 \pm 11$ & $300-500$ \\
\hline Sala de Ácessórios & $193 \pm 22,2$ & $300-500$ \\
\hline
\end{tabular}

Ao comparar os valores coletados com o que é estabelecido em norma, verifica-se que apenas o Box 10 se encontra dentro das especificações, visto que a iluminância apropriada seria um valor entre 300 e 500 lux. Ainda, se considerarmos o Box 6 , pode-se perceber que o valor se torna extremamente baixo e comprometedor para a saúde dos trabalhadores. Sendo assim, sugere-se que sejam instaladas novas luminárias nos box 1, 5, 6 e nas áreas de passagem e sala de acessórios que possuam maior capacidade (lúmens) de iluminação para atender o especificado na normativa.

Quadro 3 - Medições no nível de ruído no ambiente de trabalho da oficina mecânica.

\begin{tabular}{ccc}
\hline & Medições & Padrão \\
\cline { 2 - 3 } Ambiente. & $\begin{array}{c}\text { Ruído } \\
\text { (DB) }\end{array}$ & $\begin{array}{c}\text { Nível de Ruído } \\
\text { NR-15 }(\text { DB })\end{array}$ \\
\hline Box 1 & $79,1 \pm 3,4$ & 85 \\
Box 5 & $80,8 \pm 2,8$ & 85 \\
Box 6 & $72,2 \pm 3,2$ & 85 \\
Box 10 & $73,1 \pm 2,6$ & 85 \\
Área de passagem & $74,4 \pm 3,3$ & 85 \\
Sala de Acessórios & $68,5 \pm 1,5$ & 85 \\
\hline
\end{tabular}

Ao visualizar o Quadro 3, percebe-se que os níveis de ruído dos ambientes de trabalho da oficina em estudo estão dentro do limite de $85 \mathrm{~dB}$ estabelecidos pela NBR 15.

\subsection{Percepção da Segurança do Trabalho pelos Colaboradores}

O questionário para identificação dos riscos da empresa pela percepção dos colaboradores foi respondido por oito funcionários. Pode-se observar, conforme a (Figura 6), que todos os colaboradores relataram que o trabalho que desempenham na empresa não acarreta em problemas de saúde, e que o trabalho não é considerado estressante. Em relação à segurança, cinco colaboradores (representando $62,5 \%$ do total) consideram como boa, e todos os colaboradores relataram que nunca sofreram acidente de trabalho.

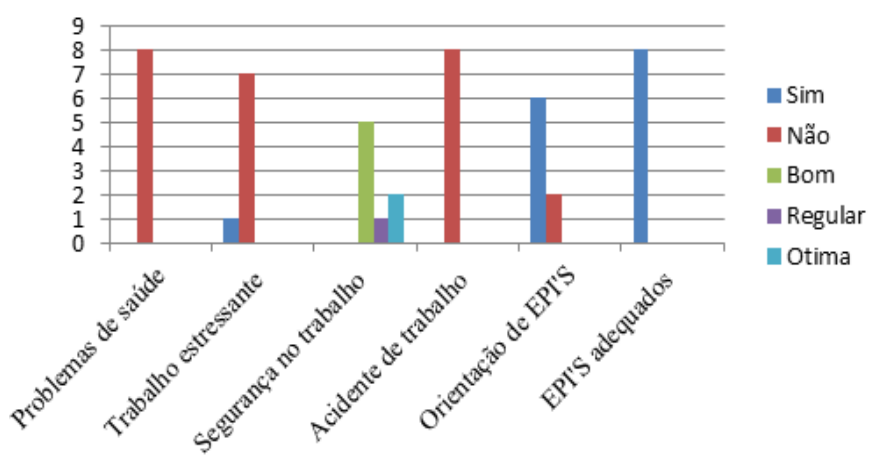

Figura 6 - Segurança do trabalho na percepção dos colaboradores.

Ainda conforme a Figura 6, em relação à orientação dos EPI's, seis colaboradores relataram que foram orientados para sua utilização (representando $75 \%$ do total) e todos consideram os EPI's adequados para a função da empresa.

Outro ponto analisado conforme a percepção dos colaboradores, foi com relação à situação crítica vivenciada no dia a dia de trabalho, em que alguns indicaram mais de uma situação como sendo crítica na empresa (Figura 7).

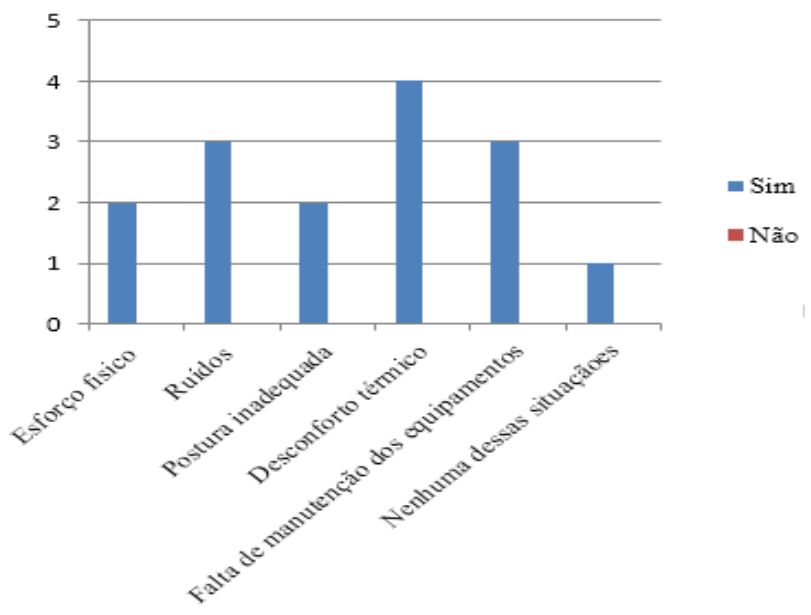

Figura 7 - Situações críticas na empresa.

A partir do gráfico 7, observa-se que as situações consideradas críticas foram esforço físico, ruídos, postura 
inadequada, desconforto térmico, falta de manutenção dos equipamentos ou nenhuma dessas situações, sendo que a maioria dos colaboradores considera como crítico o desconforto térmico.

Com relação à prevenção dos riscos do ambiente de trabalho (Figura 8), os colaboradores consideraram como prevenção a utilização de EPI's, o respeito à sinalização existente na zona de produção, a não exposição aos riscos e a realização de exames periódicos.

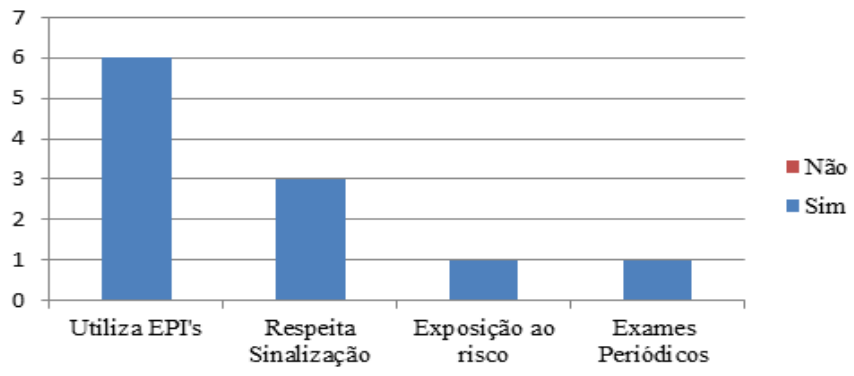

Figura 8 - Prevenção dos riscos no ambiente de trabalho.

Nota-se que existe consciência, tanto por parte da chefia como dos colaboradores, sobre a importância do uso de EPI's e do respeito aos EPC's, para garantir a qualidade e segurança do trabalho. Essa percepção se faz importante para que os colaboradores tenham conhecimento de que parte da responsabilidade da segurança no trabalho é de seus superiores, no caso de fornecimento de EPI's, EPC's e treinamentos, mas que eles próprios possuem a responsabilidade de realmente utilizarem esses equipamentos em prol de sua saúde e segurança ao exercer suas atividades e funções.

\section{Conclusões}

Por meio da realização do presente trabalho constata-se que a empresa em questão demonstra uma preocupação com a saúde e a integridade física de seus colaboradores, tendo em vista que possui programas de treinamentos referentes à segurança do trabalho e fornece equipamentos de proteção individual e coletiva.

Com relação aos riscos existentes no local de trabalho, foi identificado como sendo predominantes os riscos de acidentes, pois se percebe que a maioria das atividades desempenhadas pelos colaboradores, quando não executadas com segurança, podem acarretar em diferentes acidentes como choques elétricos, quedas de equipamentos ou ferramentas sobre o colaborador, entre outros.

Como medidas de melhoria para redução dos riscos identificados, sugere-se prestar treinamentos contra incêndio, resposta a emergências em caso de acidentes, também a disponibilização das Fichas de Informação de Segurança para Produtos Químicos (FISPQ) e a revisão dos equipamentos de proteção individual utilizados para verificação da sua eficácia para os riscos identificados. Para os riscos ergonômicos sugere-se a implantação de um programa de ginástica laboral para os trabalhadores da oficina e escritório.

A respeito da percepção de segurança no trabalho pelos colaborados, nota-se que os mesmos não consideram o trabalho estressante nem prejudicial à saúde, não relataram a ocorrência de acidentes e, de maneira geral, consideraram a segurança do trabalho como sendo boa. No entanto, relataram que o desconforto térmico é uma situação crítica vivenciada no dia a dia de trabalho. A maior parte dos colaboradores acredita que o uso de EPI's é uma forma de se prevenir os acidentes no trabalho.

Analisando o ambiente de trabalho de modo geral, o mesmo encontra-se devidamente sinalizado, porém, devido à desorganização de alguns locais, existe a possibilidade de acidentes, como quedas, ocasionados pela desordem. Sugere-se, assim, que a oficina adote práticas de organização do ambiente de trabalho como, por exemplo, a adoção e o cumprimento da metodologia $5 \mathrm{~S}$

\section{EVALUATION OF EXISTING RISKS IN A MECHANICAL OFFICE LOCATED IN THE MUNICIPALITY OF CAMPO MOURÃO / PR}

ABSTRACT: Concern about health and safety at work has become extremely relevant both for employees and for organizations, since their prevention and control contributes to the reduction of accidents and improvement of working conditions. Therefore, the objective of this work is to carry out a qualitative and quantitative evaluation of the existing risks in the workplaces of a Mechanical Workshop and to propose suggestions for improvements to the possible identified risks. The research techniques used were bibliographical, by survey, case study and field study. From the studies carried out, it was verified that the Company provides training, EPI's and EPC's for employees. In relation to risks, accidents, ergonomic, physical and chemical risks were identified. Regarding the perception of work safety, employees reported that the activities carried out do not cause health problems, and that work is not considered stressful and that they have never suffered an occupational accident. Still according to the collaborators, the most critical situation experienced in the day-to-day work is the thermal discomfort. In general, the Workshop is properly signaled, which demonstrates a concern for the health and safety of the collaborator and his clients.

Keywords: Auto mechanic, Prevention programs, Workplace safety.

\section{Referências}

[1] FERREIRA, A. S. et al. Analise Ergonômica e Aplicação do Método Owas em uma Oficina de Manutenção Mecânica de uma Usina Termoelétrica. In: 
ENCONTRO NACIONAL DE ENGENHARIA DE PRODUÇÃO, 30, 2010, São

Carlos. Anais...São Carlos: Enegep, 2010.

[2] MELLO, S. R. B. D. et al. Metodologia de Checkland Aplicada para Implementação de SGSST e da Nova NR 10 em uma Empresa do Setor Elétrico Nacional. In: ENCONTRO NACIONAL DE ENGENHARIA DE PRODUÇÃO, 30.,2010, São Carlos. Anais...São Carlos: Enegep, 2010.

[3] BRASIL, Lei No 6.367 - de 19 de outubro de 1976 - Lei de Acidentes do Trabalho, Brasília. DF, 1976.

[4] PEIXOTO, N. H. Curso técnico em automação industrial: segurança do trabalho. - 3. ed. - Santa Maria : Universidade Federal de Santa Maria: Colégio Técnico Industrial de Santa Maria, 2011.

[5] SOUZA, E. F. N; MACHADO, W. O. A Segurança do Trabalho nas Empresas: Um Estudo de seu Papel e sua Importância, Revista Diálogos Acadêmicos, Vol. 4. n. 1, p. 102-116, 2013.

[6] OLIVEIRA, O. J. et al. Gestão da segurança e saúde no trabalho em empresas produtoras de baterias automotivas: um estudo para identificar boas práticas, Revistas Produção, Vol. 20. n. 3, p. 481-490, 2010.

[7] BRASIL; MF; DATAPREV. Anuário Estatístico da Previdência Social/Ministério da Fazenda. Ano 1 (1988/1992) - Brasília: MF/DATAPREV, 2015.

[8] SILVA, N. A. A responsabilidade civil do empregador nos acidentes de trabalho. 2012. 64 f. Monografia (Graduação em Direito) - Universidade Presidente Antonio Carlos, Barbacena, 2012.

[9] SOUSA, L. M. et al. Análise da segurança e saúde no trabalho no estado do Piauí no período 2010-2013. In: INTERNATIONAL CONFERENCE ON ENGINEERING AND TECHNOLOGY EDUCATION, 14.,2016, Salvador. Anais...Salvador: Copec, 2016.

[10] CARVALHO, N. C. A. Responsabilidade civil do empregador no acidente de trabalho: meio ambiente do trabalho e seus reflexos. 2016. 52 f. Dissertação (Pós-graduação em direito) - Escola de direito de Brasília, Brasília, 2016.

[11] SEBRAE - SP. Reparação de veículos: um negócio promissor. Cartilha Técnica. São Paulo, 2015.

[12] SINDEESMAT - Sindicato dos Empregados em Escritório e Manutenção nas Empresas de Transportes de Passageiros de Curitiba e Região Metropolitana. Perigos nas oficinas mecânicas: conheça medidas de segurança. Curitiba, 2016.

[13] BRASIL, Tribunal Regional do trabalho. NR 9: Programa de Prevenção de Riscos Ambientais. São Paulo, SP, 2017.

[14] RODRIGUES, L. B. Identificação dos riscos ocupacionais em uma unidade de produção de derivados de carne, Journal Of Health Sciensces, Vol. 14, n. 2, 2012.

[15] BRASIL, Tribunal Regional do trabalho. NR 5: Comissão Interna de Prevenção de Acidentes. São Paulo, SP, 2017.

[16] BRASIL, Tribunal Regional do trabalho. NR 4: Serviço Especializado em Engenharia de Segurança e Medicina do Trabalho. São Paulo, SP, 2017.

[17] BRASIL, Tribunal Regional do trabalho. NR7: Programa de Controle Médico e Sáude Ocupacional. São Paulo, SP, 2017.
[18] Associação Brasileira de normas técnicas. NBR 15681:2009. Veículos rodoviários automotores e qualificação de mecânico de manutenção. São Paulo, 2017

[19] Associação Brasileira de normas técnicas. NBR 14788:2001. Inspeção, diagnóstico, reparação e/ou substituição em sistema de freios e o código. São Paulo, 2017.

[20] Associação Brasileira de normas técnicas. NBR 10004. Resíduos sólidos e as Normas regulamentadoras. São Paulo, 2017.

[21] BRASIL, Tribunal Regional do trabalho. NR 6: Equipamento de Proteção Individual. São Paulo, SP, 2017

[22] STANGANELLI, N. C. A utilização de equipamentos de proteção individual entre trabalhadores de enfermagem de um hospital público, Cogitare Enferm, Vol. 20, n. 2, 2015.

[23] SILVA, R. C. et al. A utilização de equipamentos de proteção individual (EPI's) por lavradores cafeeiros do município de Rosário da Limeira (MG): uma avaliação em saúde sob a ótica do enfermeiro, Revista Científica da Faminas, Vol. 6, n. 2, 2010. 